\title{
Prevalence and determinants of cannabinoid prescription for the management of chronic noncancer pain: a postal survey of physicians in the Abitibi-Témiscamingue region of Quebec
}

\author{
Huguette St-Amant MSc RN, Mark A. Ware MD MSc, Nancy Julien PhD, Anaïs Lacasse PhD
}

Abstract

Background: Few studies have been conducted to explore physicians' prescription practices and attitudes toward the use of cannabinoids in Canada. We measured the prevalence and identified determinants of cannabinoid prescription for the management of chronic noncancer pain among physicians in southwestern Quebec.

Methods: In February 2013, we conducted a postal survey using a modified Dillman method that involved physicians practising in the Abitibi-Témiscamingue region of Quebec. We used multivariate logistic regression models to identify determinants of cannabinoid prescription.

Results: A total of 166 physicians of 318 practising in the region participated in the survey (response rate $52.2 \%$ ). The prevalence of cannabinoid prescription was $27.3 \%$ (45/165) for any indication and $23.0 \%$ (38/165) for the management of chronic noncancer pain; $91.1 \%(41 / 45)$ of the physicians prescribed cannabinoids to 5 or fewer patients. Of the 38 physicians who prescribed cannabinoids for chronic noncancer pain, $35(92.1 \%)$ prescribed nabilone, $7(18.4 \%)$ medical marijuana and $2(5.3 \%)$ nabiximols. The principal determinant of cannabinoid prescription was the physician's level of comfort with prescribing cannabinoids (adjusted odds ratio 1.25, 95\% confidence interval 1.01-1.55, per 1-point increase in comfort level measured on 10-point scale). Respondents reported that continuing medical education (CME) activities could increase their comfort level. They also indicated a need for guidelines or algorithms that included cannabinoid use as well as more studies about the efficacy and safety of cannabinoids for the management of chronic noncancer pain.

Interpretation: We found that cannabinoids were not often prescribed for the management of chronic noncancer pain and that survey respondents were not comfortable with prescribing this drug class. This degree of discomfort could be addressed by CME activities, more effective dissemination of guidelines and more evidence regarding cannabinoid use for the management of chronic noncancer pain.

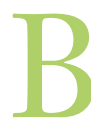
etween $11 \%$ and $29 \%$ of Canadians are affected by chronic pain, which has serious consequences for their physical functioning, mental health and quality of life. ${ }^{1-4}$ This health issue also represents a significant economic burden on the health care system. ${ }^{5,6}$ To date, the treatment of chronic noncancer pain remains suboptimal, mainly because of a lack of recognition of the condition, not enough training for health care professionals, absence of effective treatments, lack of access to pain treatment centres and suboptimal use of certain drugs. ${ }^{1,5,7-10}$

Different cannabinoid products have been found to be effective and safe for some chronic noncancer pain syndromes, such as neuropathic pain. ${ }^{11-14}$ For other conditions, such as fibromyalgia and rheumatic pain, their use raises concerns or evidence is limited. ${ }^{14,15}$ Cannabinoids are pharmaceutical products of a therapeutic class that include psychoactive constituents of the Cannabis sativa plant (delta-9-tetrahydro- cannabinol [THC]) or synthetic analogues that can be prescribed to produce analgesia via the endocannabinoid system. ${ }^{16,17}$ A number of prescription products are currently available in Canada: nabilone (oral capsules), nabiximols (buccal spray) and medical marijuana (dried cannabis). As for medical marijuana, new Canadian regulations entered into

Competing interests: Mark Ware serves and receives a stipend as executive director of a nonprofit corporation involved in preparing and delivering educational material on cannabis and cannabinoids (the Canadian Consortium for the Investigation of Cannabinoids). No other competing interests were declared.

This article has been peer reviewed.

Correspondence to: Anaïs Lacasse, lacassea@uqat.ca

CMAJ Open 2015. DOI:10.9778/cmajo.20140095 
force in April 2014. ${ }^{18}$ In this context, physicians can support patients' use of marijuana for medical purposes through the completion of a medical document with specific information that is similar to a prescription. Patients can then send this document to a licensed producer, who provides the product based on the daily amount of marijuana that is recommended by the physician.

The prevalence of cannabinoid use for the management of pain symptoms remains low $(12 \%-15 \%) .{ }^{19-22}$ This limited use among patients could be explained in part by the stigma associated with smoking marijuana, which also affects products offered in capsule or spray formulation..$^{20,23}$ Using medical marijuana is one of the treatments for which users are the most stigmatized regardless of their specific health condition. ${ }^{24}$ Moreover, the situation could be explained by physicians' lack of comfort regarding these therapeutic modalities. ${ }^{25}$ Few studies have been conducted to explore physicians' prescription practices and attitudes toward the use of cannabinoids in Canada. ${ }^{26}$

We conducted this study to measure the prevalence of cannabinoid prescription for the management of chronic noncancer pain by physicians in southwestern Quebec, and to identify the determinants of prescription.

\section{Methods}

\section{Study population and design}

We selected a convenience sample of physicians from the list of members of the Collège des médecins du Québec who were practising in Abitibi-Témiscamingue, a region in southwestern Quebec that has a population of more than 145000 . As of January 2013, 318 physicians (183 family physicians and 135 specialists) met these criteria.

In February 2013, a cross-sectional postal survey was conducted involving the 318 physicians. Updated and valid postal addresses were obtained via their professional organization 1 month before the survey. The protocol was approved by the research ethics committee of the Université du Québec en Abitibi-Témiscamingue.

Participants were asked to complete a French-language self-administered questionnaire. We used a modified Dillman survey method, ${ }^{27}$ which involved 4 rounds of postal mail-outs (Appendix 1, available at www.cmajopen.ca/content/3/2/ E251/suppl/DC1). Questionnaires were coded to be able to send reminders to nonrespondents. In the first round, an introductory letter, the questionnaire and a prepaid return envelope were mailed to participants. The second round involved a reminder postcard sent 1 week after round one. Three weeks after round one, a second copy of the questionnaire was mailed to nonrespondents. A final copy of the questionnaire was mailed to nonrespondents 7 weeks after round one; registered mail was not used for this final mailing contrary to what is suggested. ${ }^{27}$

According to recommendations, ${ }^{28-30}$ we used some additional strategies to increase the response rate: a cover letter with a blue handwritten signature and a direct telephone contact for the principal investigator, assurance of confidentiality, personalized correspondence, a 12-page maximum colourprinted questionnaire, and a teaser sentence printed on the mailing envelope. No financial incentives were offered.

\section{Questionnaire development and measures}

The questionnaire was developed specifically to study cannabinoid prescription for the treatment of chronic noncancer pain (Appendix 2, available at www.cmajopen.ca/content/ 3/2/E251/suppl/DC1). To ensure its content validity, the questionnaire was developed by pain experts. We also reviewed existing instruments, such as the Cannabinoid Education Needs Assessment tool developed by the Canadian Consortium for the Investigation of Cannabinoids (www.ccic.net) that was used in previous research. ${ }^{26}$ The questionnaire was finally pretested in a judgemental sample of 8 individuals with a graduate-level degree (i.e., physicians who were not intended to be contacted for the present study, pain experts and other health care professionals such as nurse-practitioners).

The items analyzed for the current study included closed questions to measure the prevalence of cannabinoid prescription in the year before the survey, the types of cannabinoids prescribed (nabilone, nabiximols or medical marijuana), the indications for prescription and the number of patients to whom physicians prescribed cannabinoids during the past year. We measured physicians' level of comfort with prescribing cannabinoids for chronic noncancer pain using a $0-10$ numeric rating scale $(0=$ absolutely not comfortable; $10=$ completely comfortable). We asked physicians to indicate what could increase their comfort level using a semi-closed question that was used in previous research. ${ }^{26} \mathrm{We}$ also collected information on the following characteristics of physicians: sex; years of practice; medical specialty; medical work environment frequented in the year before the survey; proportion of medical practice dedicated to seeing patients in the year before the survey; number of patients seen each week within the medical practice; perception of the prevalence of

\begin{tabular}{|c|c|c|}
\hline \multicolumn{3}{|c|}{$\begin{array}{l}\text { Table 1: Characteristics of physicians who participated in the } \\
\text { survey and those who did not complete the questionnaire }\end{array}$} \\
\hline Characteristic & $\begin{array}{c}\text { Participants, } \\
\text { no. (\%) } \\
n=166\end{array}$ & $\begin{array}{c}\text { Nonparticipants, } \\
\text { no. }(\%) \\
n=152\end{array}$ \\
\hline \multicolumn{3}{|l|}{ Sex } \\
\hline Male & $77(46.4)$ & $81(53.3)$ \\
\hline Female & $89(53.6)$ & $71(46.7)$ \\
\hline \multicolumn{3}{|l|}{ Medical specialty } \\
\hline $\begin{array}{l}\text { Family physician/ } \\
\text { general practitioner }\end{array}$ & $93(56.0)$ & $87(57.2)$ \\
\hline Other specialty & $73(44.0)$ & $65(42.8)$ \\
\hline \multicolumn{3}{|c|}{ Location of health services centre } \\
\hline Rouyn-Noranda & $62(37.3)$ & $34(22.4)$ \\
\hline Vallée-de-l'Or & $46(27.7)$ & $34(22.4)$ \\
\hline Other† & $58(34.9)$ & $84(55.3)$ \\
\hline
\end{tabular}




\section{Table 2: Characteristics of participating physicians}

\begin{tabular}{|c|c|c|c|}
\hline \multirow[b]{2}{*}{ Characteristic } & \multicolumn{3}{|c|}{ No. $(\%)$ of respondents* } \\
\hline & $\begin{array}{c}\text { Total } \\
n=166\end{array}$ & $\begin{array}{l}\text { Did not prescribe } \\
\text { cannabinoids } n=127\end{array}$ & $\begin{array}{c}\text { Prescribed } \\
\text { cannabinoids } n=38\end{array}$ \\
\hline \multicolumn{4}{|l|}{ Sex } \\
\hline Male & $77(46.4)$ & $59(46.5)$ & $18(47.4)$ \\
\hline Female & $89(53.6)$ & $68(53.5)$ & $20(52.6)$ \\
\hline Years of practice & $n=162$ & $n=123$ & \\
\hline$\leq 5$ & $30(18.5)$ & $24(19.5)$ & $6(15.8)$ \\
\hline $6-10$ & $20(12.3)$ & $14(11.4)$ & $6(15.8)$ \\
\hline $11-20$ & $50(30.9)$ & $41(33.3)$ & $9(23.7)$ \\
\hline$\geq 21$ & $62(38.3)$ & $44(35.8)$ & $17(44.7)$ \\
\hline Medical specialty & & $n=127$ & \\
\hline Family physician/general practitioner & $93(56.0)$ & $60(47.2)$ & $32(84.2)$ \\
\hline Other specialty & $73(44.0)$ & $67(52.8)$ & $6(15.8)$ \\
\hline Work environment frequented in past year $\dagger$ & $n=163$ & $n=124$ & \\
\hline Hospital (excluding emergency department) & $87(53.4)$ & $74(59.7)$ & $13(34.2)$ \\
\hline Family medicine group or unit & $43(26.4)$ & $25(20.2)$ & $17(44.7)$ \\
\hline Emergency department & $35(21.5)$ & $26(21.0)$ & $9(23.7)$ \\
\hline Private medical office & $21(12.9)$ & $13(10.5)$ & $8(21.1)$ \\
\hline Environment offering palliative care & $11(6.7)$ & $4(3.2)$ & $7(18.4)$ \\
\hline Local community services centre & $12(7.4)$ & $8(6.5)$ & $4(10.5)$ \\
\hline Long-term care facility & $8(4.9)$ & $3(2.4)$ & $5(13.2)$ \\
\hline Abitibi-Témiscamingue health and social services agency & $6(3.7)$ & $5(4.0)$ & $1(2.6)$ \\
\hline Other & $5(3.1)$ & $4(3.2)$ & $1(2.6)$ \\
\hline$\%$ of medical practice dedicated to seeing patients in past year & $n=160$ & $n=121$ & \\
\hline Mean \pm SD & $82.4 \pm 24.2$ & $80.3 \pm 28.4$ & $86.3 \pm 14.0$ \\
\hline Median & 90 & 90 & 90 \\
\hline$\%$ of medical practice dedicated to seeing patients in past year & $n=160$ & $n=121$ & \\
\hline$<50 \%$ & $13(8.1)$ & $12(9.9)$ & $1(2.6)$ \\
\hline$\geq 50 \%$ & $147(91.9)$ & $109(90.1)$ & $37(97.4)$ \\
\hline No. of patients seen each week in medical practice & $n=163$ & $n=124$ & \\
\hline Mean \pm SD & $58.4 \pm 37.2$ & $52.3 \pm 33.1$ & $73.6 \pm 47.3$ \\
\hline Median & 50 & 50 & $60 \mathrm{H}$ \\
\hline Perception of CNCP prevalence among clientele & $n=159$ & $n=120$ & \\
\hline Mean \pm SD & $22.1 \pm 17.4$ & $19.7 \pm 15.1$ & $28.6 \pm 22.2$ \\
\hline Median & 20 & 20 & 20 \\
\hline Perception of CNCP prevalence among clientele & $n=159$ & $n=120$ & \\
\hline$<50 \%$ of patients & $146(91.8)$ & $111(92.5)$ & $34(89.5)$ \\
\hline$\geq 50 \%$ of patients & $13(8.2)$ & $9(7.5)$ & $4(10.5)$ \\
\hline$\%$ of CME activities about CNCP and its treatment in past year & $n=159$ & $n=121$ & $n=37$ \\
\hline 0 & $54(34.0)$ & $51(42.1)$ & $3(8.1)$ \\
\hline $1-10$ & $71(44.7)$ & $50(41.3)$ & $21(56.8)$ \\
\hline $11-20$ & $28(17.6)$ & $18(14.9)$ & $9(24.3)$ \\
\hline $21-30$ & $4(2.5)$ & $1(0.8)$ & $3(8.1)$ \\
\hline $31-40$ & $2(1.3)$ & $1(0.8)$ & $1(2.7)$ \\
\hline$\%$ of CME activities about cannabinoids in past year & $n=159$ & $n=120$ & \\
\hline 0 & $126(79.2)$ & $104(86.7)$ & $22(57.9)$ \\
\hline $1-20$ & $33(20.8)$ & $16(13.3)$ & $16(42.1)$ \\
\hline $\begin{array}{l}\text { Level of comfort with prescribing cannabinoids for CNCP } \\
\text { (10-point scale), mean } \pm \text { SD }\end{array}$ & $\begin{array}{l}n=155 \\
2.5 \pm 2.8\end{array}$ & $\begin{array}{l}n=116 \\
1.4 \pm 1.9\end{array}$ & $5.9 \pm 2.5$ \\
\hline
\end{tabular}


chronic noncancer pain among their patients; and the proportion of continuing medical education (CME) activities about chronic noncancer pain or cannabinoids attended in the year before the survey.

\section{Statistical analysis}

In addition to descriptive statistics, we used multivariate logistic regression models to identify the determinants of cannabinoid prescription for the management of chronic noncancer pain. Results are presented as odds ratios (ORs) with their respective $95 \%$ confidence intervals (95\% CIs). The choice of variables to be included in the final multivariate model was based on their association with the dependant variable (all predictors with a $p$ value $\leq 0.15$ in the univariate logistic regression models). We decided a priori to force the number of years in practice into to the final model. Statistical power of the multivariate models was assured with the following rule of thumb: sample size $\div 20=$ number of variables that can be included in the multivariate model. ${ }^{31,32} \mathrm{We}$ conducted all statistical analyses using IBM SPSS Statistics version 19 .

\section{Results}

\section{Physician characteristics}

A total of 166 physicians participated in the survey (response rate $52.2 \%$ ). They were similar to the 152 nonrespondents in terms of sex and medical specialty but not in terms of geographic distribution (Table 1). Physicians from RouynNoranda were more likely than the other physicians to return their questionnaire. Of the nonrespondents, 6 called or wrote to the researchers to discuss their reasons for not participating, which were not being in clinical practice $(n=1)$, not treating chronic noncancer pain $(n=1)$, not prescribing prescription drugs $(n=3)$ and considering cannabinoids to be against their values $(n=1)$. Table 2 shows the characteristics of the participating physicians. Overall, 56.0\% were family physicians. Most (79.2\%) of the respondents had not attended CME activities about cannabinoids in the year before the survey.

\section{Cannabinoid prescribing}

The prevalence of cannabinoid prescriptions for all potential indications in the year before the survey was $27.3 \%(45 / 165)$. The prevalence of cannabinoid prescription specifically for the management of chronic noncancer pain was $23.0 \%$ (38/165) (Figure 1); 91.1\% (41/45) of physicians prescribed cannabinoids to 5 or fewer patients during the past year. Of the 38 physicians who prescribed cannabinoids for chronic noncancer pain, 35 (92.1\%) prescribed nabilone, 7 (18.4\%) medical marijuana and $2(5.3 \%)$ nabiximols.

When we stratified the prevalence of cannabinoid prescription by medical specialty, we found that $34.8 \%$ (32/92) of family physicians had prescribed cannabinoids for chronic noncancer pain in the year before the survey, as compared with $8.2 \%(6 / 73)$ of specialists $(p<0.05)$.

\section{Comfort with cannabinoid prescribing}

Figure 2 shows the level of comfort respondents reported with prescribing cannabinoids. A minority of them reported a



Figure 1: Prevalence of cannabinoid prescription in the year before the survey among participating physicians practising in the Abitibi-Témiscamingue region of Quebec, by therapeutic indication. CNCP $=$ chronic noncancer pain. Data were missing for $0.6 \%$ of respondents. 
comfort level of 6 or higher on the $0-10$ numeric rating scale for prescribing cannabinoids in general $(17.3 \%$ [27/156]) or for managing chronic noncancer pain (19.4\% [30/155]). When asked what factors could increase their comfort level with prescribing cannabinoids for chronic noncancer pain, the majority of respondents (cannabinoid prescribers and nonprescribers alike) mentioned attending CME activities about cannabinoids (68.4\% [104/152]), having guidelines and algorithms that included cannabinoid prescribing $(67.1 \%$

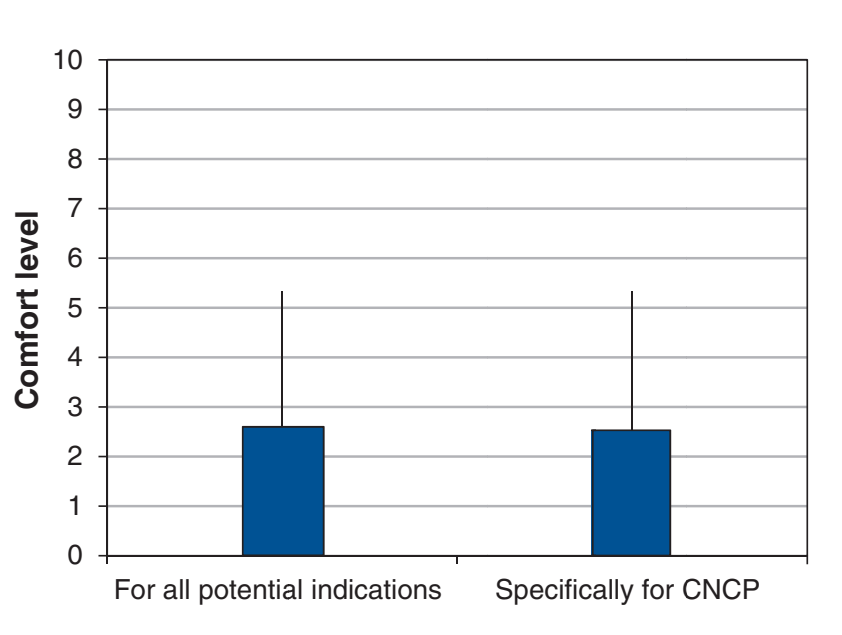

Figure 2: Respondents' level of comfort (measured on a 10-point scale) with prescribing cannabinoids for all indications and for chronic noncancer pain (CNCP) specifically. Data were missing for $6.0 \%-$ $6.6 \%$ of respondents. Error bars $=$ standard deviations.
[102/152]) and having more clinical data and new studies $(50.0 \%[76 / 152])$.

\section{Determinants of cannabinoid prescribing}

Table 3 shows the variables associated with the prescription of cannabinoids for the management of chronic noncancer pain. In the univariate regression models, which did not allow for the consideration of intercorrelations between independent variables, statistically significant factors were medical specialty (specialist v. family physician, OR 0.17 , 95\% CI $0.07-0.43$ ), practising mostly in a hospital environment (OR $0.35,95 \%$ CI $0.16-0.75)$, practising mostly in a family medicine group or unit (OR 3.21, 95\% CI 1.48-6.96), increased weekly patient caseload (OR 1.02, 95\% CI 1.01-1.03, per 1 -patient increase in weekly caseload), higher perception of prevalence of chronic noncancer pain among clientele (OR $1.03,95 \%$ CI $1.01-1.05$, per $10 \%$ increase in perceived prevalence) and higher level of comfort with prescribing cannabinoids for chronic noncancer pain (OR 2.04, 95\% CI 1.642.54, per 1-point increase in comfort level). In the final multivariate model, only a higher level of comfort with prescribing cannabinoids for chronic noncancer pain remained a significant factor (adjusted OR 1.25, 95\% CI 1.01-1.55, per 1-point increase).

Figure 3 shows more specifically the correlation between respondents' comfort level with prescribing cannabinoids for chronic noncancer pain and the prevalence of cannabinoid prescription for that indication. Results indicate that $83 \%$ of the variance in the prevalence of cannabinoid prescription can be explained by the respondents' comfort level.

Table 3: Factors associated with the prevalence of cannabinoid prescription for the management of chronic noncancer pain (CNCP)

\begin{tabular}{|c|c|c|}
\hline Variable & $\begin{array}{c}\text { Crude OR } \\
(95 \% \mathrm{Cl})\end{array}$ & $\begin{array}{l}\text { Adjusted OR } \dagger \\
\quad(95 \% \mathrm{Cl})\end{array}$ \\
\hline Sex, female (v. male) & $0.96(0.47-1.99)$ & - \\
\hline Years of practice $\geq 21(\mathrm{v} .<21)$ & $1.26(0.41-3.81)$ & $0.70(0.17-2.84)$ \\
\hline Other medical specialty (v. family physician/general practitioner) & $0.17(0.07-0.43)$ & $0.14(0.01-1.71)$ \\
\hline \multicolumn{3}{|l|}{ Work environment frequented in past year (yes v. no) } \\
\hline Hospital environment (excluding emergency department) & $0.35(0.16-0.75)$ & $1.90(0.42-8.51)$ \\
\hline Family medicine group or unit & $3.21(1.48-6.96)$ & $1.52(0.40-5.86)$ \\
\hline Emergency department & $1.17(0.49-2.78)$ & - \\
\hline Private medical office & $2.28(0.86-6.00)$ & $1.33(0.29-6.15)$ \\
\hline$\%$ of medical practice dedicated to seeing patients in past year, per $10 \%$ increase in proportion & $1.01(0.99-1.03)$ & - \\
\hline No. of patients seen each week in medical practice, per 1-patient increase in weekly caseload & $1.02(1.01-1.02)$ & $1.01(0.99-1.02)$ \\
\hline Perception of CNCP prevalence among clientele, per $10 \%$ increase in perceived prevalence & $1.03(1.01-1.05)$ & $1.01(0.98-1.04)$ \\
\hline$>10 \%$ of CME activities about CNCP in past year (v. $\leq 10 \%)$ & $1.04(0.27-3.95)$ & - \\
\hline$\geq 1 \%$ of CME activities about cannabinoids in past year (v. $0 \%)$ & $1.66(0.48-5.67)$ & - \\
\hline Level of comfort with prescribing cannabinoids for CNCP, per 1-point increase on comfort scale & $2.04(1.64-2.54)$ & $1.25(1.01-1.55)$ \\
\hline
\end{tabular}




\section{Interpretation}

Our survey showed that as many as $23.0 \%$ of survey respondents reported prescribing cannabinoid for the management of chronic noncancer pain; however, the vast majority prescribed it to only 5 or fewer patients. Respondents were not comfortable prescribing cannabinoids for chronic noncancer pain, with about $80 \%$ reporting a degree of comfort below 6 on the 10 -point scale. Independent of respondents' other characteristics, the degree of comfort with prescribing cannabinoids was the only significant determinant of cannabinoid prescription for chronic noncancer pain. As a way of increasing their comfort level, they indicated a need for more evidence regarding the use of cannabinoids for chronic noncancer pain and the establishment of guidelines or algorithms that included cannabinoid prescribing. Guidelines for the management of chronic pain that include these therapeutic agents exist, ${ }^{33-35}$ but our findings suggest that they need more effective dissemination.

A large number of the respondents had not attended a training session about chronic noncancer pain or about the use of cannabinoids in the year before the survey, but CME activities were identified by respondents as a way that could increase their comfort level. Previous studies have shown that Canadian health care professionals want better training in the treatment of chronic pain; ${ }^{37-39}$ therefore, it would be beneficial to increase the number of training opportunities.

Few studies of this kind have been conducted with samples of physicians. In a Canadian study by Ziemianski and colleagues, ${ }^{26}$ the prevalence of cannabinoid prescription was $35 \%$ among family physicians and 33\% among specialists. Once we stratified prescription prevalence by medical specialty in our study, the rate among family physicians was similar (34.8\%), but it was much lower among specialists (8.2\%). This difference could be explained by the fact that their study was not

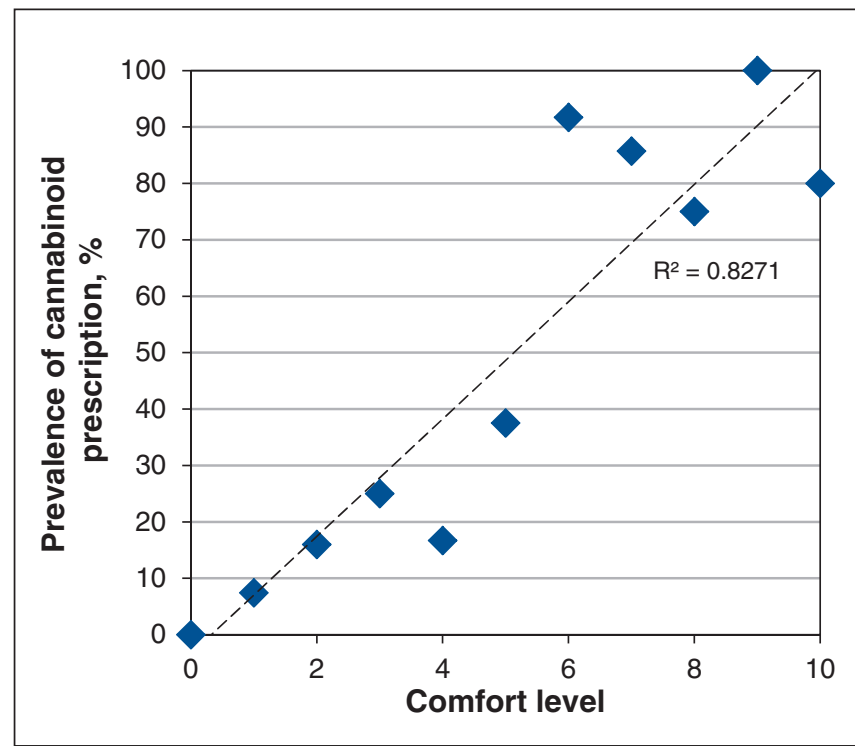

Figure 3: Correlation between respondents' level of comfort (measured on a 10-point scale) with prescribing cannabinoids for chronic noncancer pain and the prevalence of cannabinoid prescription for that indication. specific to chronic noncancer pain and that their sample was composed of physicians who participated in CME activities about cannabinoids. Their sample may have been more representative of physicians interested in this drug class and not necessarily representative of all physicians. Past research has also found that having a personal positive experience with medical or recreational use of marijuana could increase physicians' degree of comfort with prescribing cannabinoids. ${ }^{36}$ However, this was not assessed in our study.

\section{Strengths and limitations}

Our study has a number of strengths, such as the use of a standardized method to collect data, the inclusion of numerous potential confounding variables in the data analyses, a high response rate in the context of a physician survey and satisfactory statistical power owing to the sample size. Surveys conducted among physicians often result in low response rates. ${ }^{40-42}$ For example, response rates to general Canadian surveys about physicians' attitudes, knowledge and practices were reported to range from $18 \%$ to $34 \% .{ }^{41,43,44}$ The response rate to our survey is more comparable to rates reported in previous surveys that focused on prescription practices and attitudes of Canadian physicians regarding the pharmacologic treatment of chronic pain $(49 \%-70 \%) .45-47$

Regarding limitations, even though the participating and nonparticipating physicians were similar in a number of characteristics, more physicians from one centre participated compared with physicians in the other centres of the study region. Also, nonrespondents may have decided not to complete the questionnaire because they do not prescribe cannabinoids or are not comfortable with prescribing them. If that is true, our results may represent an overestimation of the prevalence of cannabinoid prescription. Our results may not be generalizable to all clinical settings in Canada, but the specific training needs identified by the respondents would be generalizable to other physicians not familiar with this drug class.

\section{Conclusion}

We found that cannabinoids were not often prescribed for the management of chronic noncancer pain and that survey respondents were not comfortable with prescribing this drug class. This degree of discomfort could be addressed by CME activities, more effective dissemination of guidelines and more evidence regarding cannabinoid use for the management of chronic noncancer pain. Researchers and educators must work with physicians for optimal and informed use of cannabinoids.

\section{References}

1. Ashburn MA, Staats PS. Management of chronic pain. Lancet 1999;353:1865-9.

2. Reitsma M, Tranmer JE, Buchanan DM, et al. The epidemiology of chronic pain in Canadian men and women between 1994 and 2007: results from the longitudinal component of the National Population Health Survey. Pain Res Manag 2012;17:166-72.

3. Gureje O, Von Korff M, Simon GE, et al. Persistent pain and well-being: a World Health Organization study in primary care. FAMA 1998;280:147-51.

4. Ohayon MM, Schatzberg AF. Using chronic pain to predict depressive morbidity in the general population. Arch Gen Psychiatry 2003;60:39-47.

5. Kronborg C, Handberg G, Axelsen F. Health care costs, work productivity and activity impairment in non-malignant chronic pain patients. Eur 7 Health Econ $2009 ; 10: 5-13$. 
6. Guerriere DN, Choiniere M, Dion D, et al. The Canadian STOP-PAIN project Part 2: What is the cost of pain for patients on waitlists of multidisciplinary pain treatment facilities? Can 7 Anaesth 2010;57:549-58.

7. MacDonald NE, Flegel K, Hebert PC, et al. Better management of chronic pain care for all. CMA7 2011;183:1815.

8. Sarzi-Puttini P, Vellucci R, Zuccaro SM, et al. The appropriate treatment of chronic pain. Clin Drug Investig 2012;32(Suppl 1):21-33.

9. Zuccaro SM, Vellucci R, Sarzi-Puttini P, et al. Barriers to pain management: focus on opioid therapy. Clin Drug Investig 2012;32(Suppl 1):11-9.

10. Sessle BJ. The pain crisis: what it is and what can be done. Pain Res Treat 2012; 2012:703947.

11. Bonfá L, Vinagre RC, de Figueiredo NV. Cannabinoids in chronic pain and palliative care. Rev Bras Anestesiol 2008;58:267-79.

12. Cohen SP. Cannabinoids for chronic pain. BM7 2008;336:167-8.

13. Elikkottil J, Gupta P, Gupta K. The analgesic potential of cannabinoids. 7 Opioid Manag 2009;5:341-57

14. Lynch ME, Campbell F. Cannabinoids for treatment of chronic non-cancer pain: a systematic review of randomized trials. Br 7 Clin Pharmacol 2011;72: 735-44.

15. Fitzcharles MA, Clauw DJ, Ste-Marie PA, et al. The dilemma of medical marijuana use by rheumatology patients. Arthritis Care Res (Hoboken) 2014;66: 797-801.

16. Russo EB. Cannabinoids in the management of difficult to treat pain. Therapeutics and clinical risk management. Ther Clin Risk Manag 2008;4:245-59.

17. Howard P, Twycross R, Shuster J, et al. Cannabinoids. 7 Pain Symptom Manage 2013;46:142-9.

18. Medical use of marijuana. Ottawa: Health Canada; 2014. Available: www.hc-sc gc.ca/dhp-mps/marihuana/index-eng.php (accessed 2015 June 10).

19. Choinière $M$, Dion $D$, Peng $P$, et al. The Canadian STOP-PAIN project: Part 1: Who are the patients on the waitlists of multidisciplinary pain treatment facilities? Can 7 Anaesth 2010;57:539-48.

20. Clark AJ, Ware MA, Yazer E, et al. Patterns of cannabis use among patients with multiple sclerosis. Neurology 2004;62:2098-100.

21. Ware MA, Doyle CR, Woods R, et al. Cannabis use for chronic non-cancer pain: results of a prospective survey. Pain 2003;102:211-6.

22. Ste-Marie PA, Fitzcharles MA. Cannabinoid use in fibromyalgia is associated with male gender, opioid use and drug seeking behaviour. Pain Res Manag 2012;17:224.

23. Gill A, Williams AC. Preliminary study of chronic pain patients' concerns about cannabinoids as analgesics. Clin 7 Pain 2001;17:245-8.

24. Bottorff JL, Bissell LJ, Balneaves LG, et al. Perceptions of cannabis as a stigmatized medicine: a qualitative descriptive study. Harm Reduct 7 2013;10:2

25. Juurlink DN. Medicinal cannabis: Time to lighten up? CMA7 2014;186:897-8

26. Ziemianski D, Tekanoff R, Luconi F, et al. Cannabinoids in clinical practice: experiences and educational needs. Pain Res Manag 2012;17:229.

27. Dillman DA. Mail and telephone surveys. New York: Wiley Interscience; 1978.

28. Field TS, Cadoret CA, Brown ML, et al. Surveying physicians: Do components of the "Total Design Approach" to optimizing survey response rates apply to physicians? Med Care 2002;40:596-605.

29. Thorpe C, Ryan B, McLean SL, et al. How to obtain excellent response rates when surveying physicians. Fam Pract 2009;26:65-8.

30. Hoddinott SN, Bass MJ. The Dillman total design survey method. Can Fam Physician 1986;32:2366-8.

31. Vittinghoff E, McCulloch CE. Relaxing the rule of ten events per variable in logistic and Cox regression. Am f Epidemiol 2007;165:710-8.

32. Harrell FE Jr, Lee KL, Mark DB. Multivariable prognostic models: issues in developing models, evaluating assumptions and adequacy, and measuring and reducing errors. Stat Med 1996;15:361-87.

33. Clark AJ, Lynch ME, Ware M, et al. Guidelines for the use of cannabinoid compounds in chronic pain. Pain Res Manag 2005;10(Suppl A):44A-6A.

34. Attal N, Cruccu G, Haanpaa M, et al. EFNS guidelines on pharmacological treatment of neuropathic pain. Eur 7 Neurol 2006;13:1153-69.
35. Moulin D, Boulanger A, Clark AJ, et al. Pharmacological management of chronic neuropathic pain: revised consensus statement from the Canadian Pain Society. Pain Res Manag 2014;19:328-35.

36. Kondrad E, Reid A. Colorado family physicians' attitudes toward medical marijuana. 7 Am Board Fam Med 2013;26:52-60.

37. Bergeron D, Gallagher F, Bourgault P. Analyse des activités en gestion de la douleur chronique réalisées par le personnel infirmier des groupes de médecine de famille (GMF). Pain Res Manag 2011;16:102.

38. Leroux-Lapointe $\mathrm{V}$, Choinière $\mathrm{M}$, Dion $\mathrm{D}$, et al. The ACCORD program: knowledge, attitudes and beliefs of community pharmacists about non-cancer chronic pain. Can 7 Clin Pharmacol 2010;17:e-116.

39. Boulanger A, Clark AJ, Squire P, et al. Chronic pain in Canada: Have we improved our management of chronic noncancer pain? Pain Res Manag 2007; 12:39-47.

40. McAvoy BR, Kaner EF. General practice postal surveys: A questionnaire too far? BM7 1996;313:732-3.

41. Grava-Gubins I, Scott S. Effects of various methodologic strategies: survey response rates among Canadian physicians and physicians-in-training. Can Fam Physician 2008;54:1424-30.

42. VanGeest JB, Johnson TP, Welch VL. Methodologies for improving response rates in surveys of physicians: a systematic review. Eval Health Prof 2007;30:303-21.

43. National Physician Survey: 2010 response rates. Ottawa: Canadian Institute of Health Information; 2010

44. National Physician Survey: 2013 response rates. Ottawa: Canadian Institute of Health Information; 2013

45. Morley-Forster PK, Clark AJ, Speechley M, et al. Attitudes toward opioid use for chronic pain: a Canadian physician survey. Pain Res Manag 2003;8:189-94.

46. Scanlon MN, Chugh U. Exploring physicians' comfort level with opioids for chronic noncancer pain. Pain Res Manag 2004;9:195-201.

47. Wenghofer EF, Wilson L, Kahan M, et al. Survey of Ontario primary care physicians' experiences with opioid prescribing. Can Fam Physician 2011;57:324-32.

Affiliations: Département des sciences de la santé (St-Amant, Julien, Lacasse), Université du Québec en Abitibi-Témiscamingue, RouynNoranda, Que.; Alan Edwards Pain Management Unit (Ware), McGill University Health Centre, Montréal, Que.

Contributors: As part of her master's thesis, Huguette St-Amant contributed to the conception and design of the study, the acquisition of data, and the analysis and interpretation of data under the supervision of Anaï Lacasse and Nancy Julien. Mark Ware contributed substantially to the conception of the questionnaire and the interpretation of data. Huguette St-Amant drafted the manuscript, and Mark Ware, Nancy Julien and Anais Lacasse critically revised it. All of the authors approved the final version to be published and agreed to act as guarantors of the work.

Funding: This study was funded by the Fonds institutionnel de développement de la recherche et de la création of Université du Québec en AbitibiTémiscamingue. We certify that there is no conflict of interest with any funding organization regarding the material discussed in the manuscript.

Acknowledgements: The authors thank Geneviève L. Lavigne $\mathrm{PhD}$, who helped with the manuscript and provided critical comments. They also thank the physicians who participated in the survey. Huguette StAmant was supported by master's scholarships from the Canadian Pain Society and the Quebec Pain Research Network.

Supplemental information: For reviewer comments and the original submission of this manuscript, see www.cmajopen.ca/content/3/2/E251/ suppl/DC1 